\title{
Glycemic Response of Natural Sweeteners like Sugarcane Juice, Honey and Jaggery in Healthy Individuals
}

Amir Iqbal, Hafsa Kamran, Sidra Khalid*, Shaista Jabeen, Maria Aslam University institute of Diet and Nutritional Sciences, Faculty of allied Health Sciences, The University of Lahore, Pakistan

Article History

Received: 01.10 .2020

Accepted: 15.10 .2020

Published: 23.10 .2020

Journal homepage: https://www.easpublisher.com/easjhcs

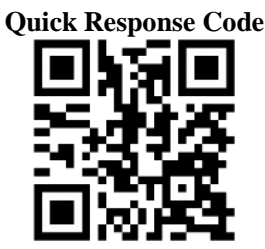

Abstract: Use of simple sugars, artificial and processed sweeteners enhances the risk of diabetes and obesity. People were unaware of benefits of natural sweeteners. An experimental study based on sample size of 10 participants was conducted, to find out the glycemic response of natural sweeteners like sugarcane juice, honey and jaggery in healthy individuals. They were instructed to consume all the juice served in a period of $5 \mathrm{~min}$. Further blood samples were taken at $0,30,60,90,120$ and 150 minutes after consumption. Participants were remained sedentary during each session. Blood was obtained by fingerprick and tested by the glucometer. Dextrose means values 91.3, 138.5, 116.7, 96.2, 88.3, 80.9. Honey mean values 84.5115 .596 .179 .772 .7 75.4. Jaggery mean values $87.4,129.6$, 103.1, 90.4, 86, 80.7. Sugarcane juice means values 83.3, 102.1, 97.4, 91.9, 76.6, 74.6 at 0 , $30,60,90,120,150$ minutes respectively. In conclusion, detailed study of glycemic values of dextrose, honey, jaggery and sugarcane juice shows that all are good glycemic substances. So, healthy persons can be recommended to use natural sweeteners because of their good glycemic response and nutrient value. Being natural sweeteners (honey, jaggery, sugarcane) they have pure nutrient value and they boost up blood sugar level energizing the body to carry out the daily activities in a healthy way without making people obese.

Keywords: Glycemic response, Knowledge, Attitudes, BMI, Natural sweeteners, Diabetes, Hypertension.

Copyright (C) 2020 The Author(s): This is an open-access article distributed under the terms of the Creative Commons Attribution 4.0 International License (CC BY-NC 4.0) which permits unrestricted use, distribution, and reproduction in any medium for non-commercial use provided the original author and source are credited.

\section{INTRODUCTION}

The glycemic index was invented in 1981 by David Jenkins and Thomas Wolver to classify carbohydrates containing foods according to their ability that how fast they increase blood sugar levels in body [1]. The glycemic response is a proportion of the effect of sustenance on blood glucose levels. Nourishment with quicker rates of processing and retention of sugars cause blood glucose levels to increment coming about most elevated glycemic reaction in contrast with those with lower glycemic reaction in which glucose is discharges gradually into blood and is critical in the control of diabetes [2]. The food and its composition of starch and its digestion rate are blood glucose determinants [3]. Glycemic index and glycemic load are diverse terms utilized for glycemic response [4]. Differences in the thickness of semi-solid foods would similarly affect glycemic response. Viscosity of food may modulate insulin and glucose response [5]. Two kinds of sugars are available i.e. common sugars of plant origin and artificial sweeteners. Sweetening agents increase the perception of sweet taste. Natural sweeteners are flavored over synthetic sweeteners since they don't have adverse effects on health. Non-saccharide is low calorific, nontoxic and too sweet in nature and can defeat the issues of sucrose and artificial sweeteners [6]. High glycemic load diets are thought to be weight gain diets because of higher postprandial insulin reaction following ingestion of a high glycemic load dinner, which stimulates uptake of glucose by insulin responsive tissues, prompting a fall in blood glucose focus and more suppression of free fatty acids [7]. Diets high in glycemic load may increase CVD risks through postprandial hyper-insulinemia and insulin obstruction prompting dyslipidemia and irritation and through postprandial hyperglycemia by inciting oxidative pressure, which adversely impacts circulatory system clot formation, and endotheliumdependent blood flow [8]. Vegetables, pasta, leafy foods items are classified low glycemic index foods (55 or less on the glucose reference scale). breads, breakfast grains, rice and snack items, including the whole grains, are accessible in both high (70 or more) and low glycemic list frames. Mostly varieties of rice and potato are high glycemic index foods [9]. The utilization of high glycemic index foods is noted to increase chances of diabetes while the utilization of low glycemic list diets may cause weight reduction and glycemic control. In any case, the blend of activity preparing with weight control plans differs by glycemic index [10]. The utilization of foods and beverages containing nonnutritive sugars has significantly expanded in the course of the last few years [11]. Characteristics sugars like nectar have numerous therapeutic properties, including antibacterial, hepatoprotective, cell reinforcements and 
anti-hypertensive impacts. It lessens hyperglycemia in diabetes [12].

Sugarcane juice is a characteristic beverage well known in most tropical Asian areas. Sugarcane juice is successful during exercise in comfortable environment to regulate blood sugar levels [13]. Jaggery is sugarcane-based product made by the concentration of sugarcane juice with no utilization of chemicals. It is accessible as strong squares and in semi-fluid structure. It contains the natural vitamins and minerals and nutrients innately present in sugarcane juice and it is one of the healthiest sugars in the world. The nutrients present in the jaggery have anti carcinogenic and antitoxic properties [14]. High glycemic load diets apparently improve craving and advance positive vitality balance [15]. Increase in protein content and an unassuming decrease in the glycemic record prompted support of weight loss [16]. The glycemic index illustrates how quick a carbohydrate food increase sugar levels in the blood. High glycemic index of a food indicates its rapid action in increasing glucose levels and is less beneficial to control sugar whereas a food with low glycemic index value is more beneficial in this regard. Use of non-nutritive foods items and beverages has hiked up in recent years [17].

Consumption of simple sugars and artificial sweeteners in the form of carbonated drinks is common now days. People are unaware of benefits of natural sweeteners like honey, jaggery and sugarcane juice. These are antioxidants which prevent from various kind of diseases and are also rich in nutrients. Study was aimed to find out the glycemic response of natural sweeteners in healthy individuals so that awareness could be created regarding use of natural sweeteners.

\section{METHODOLOGY}

To carry out the research an experimental study was designed and experiments were performed in Nutrition lab 101, University Institute of Diet and Nutritional Sciences, Faculty of Allied Health Sciences, The University of Lahore. Total of 10 healthy individuals with no previous medical diagnosis (aged between 18 to 45 years) were selected for the study period of 4 months. Diabetic, Obese or individuals with any other medical diagnosis, or people below or above the age limit were excluded.

\section{STUDY PROTOCOL}

Subjects were examined physically and anthropometrically. Day before a test subjects were asked to restrict their participation in intense physical activity. The entire products sample prepared contained $50 \mathrm{gm}$ carbohydrates in $500 \mathrm{ml}$ solution. After a $12 \mathrm{hr}$. night fasting blood sample were taken and then prepared sample were provided to the subjects that they have to consume in 5 minutes. Further blood samples were taken at $0,30,60,90,120$ and 150 minutes. New lancet were used at every finger prick. Alcohol swab were used for cleaning finger. New packed sugar sticks were used at every blood sample. Accu-check glucometer were used to find out the sugar levels. Results of samples were noted on time. Subjects were remaining sedentary during each session of experiment.

\section{RESULTS}

Study included 6 subjects were aged between 18 to 27 years and 4 subjects were aged between 31 to 44 years and the mean age of these subjects was 29.2. Among the total participants 5 were males and 5 were females. According to the body mass index 4 subjects were having normal BMI and 6 subjects were having overweight. According to the results 3 subjects were smokers and 7 were non-smokers. According to the results 2 subjects were taking 7-8 hrs. Sleep, 2 were sleeping 8-9 hrs. 3 subjects were sleeping 8-10 hrs. 1 subject was sleeping 9-10 hrs. And 2 subjects were taking sleep 10-12 hrs. Sleep. According to the results 9 subjects were having table sugar and 1 subject was having Jaggery as sweetener. Results showed that 8 subjects preferred whole wheat chapatti and 2 subjects preferred white floor chapatti. 1 subject preferred Brown rice and 9 subjects preferred white rice. According to the results 7 subjects preferred whole fruit and 3 subjects were preferring fruit juices. According to the results 5 subjects preferred white sugar, 4 subjects were preferred brown sugar and 1 subject was prefers jiggery, Table 1. 
Table-1: Frequency distribution of subjects according to attributes:

\begin{tabular}{|c|c|c|}
\hline Sr.no & ATTRITUBES & FREQUENCY \\
\hline 1 & No of participants & - 10 \\
\hline 2 & Gender & $\begin{array}{ll}\text { - } & 5 \text { Males } \\
\text { - } & 5 \text { Females } \\
\end{array}$ \\
\hline 3 & Age limit & - $18-45$ years \\
\hline 4 & BMI & $\begin{array}{ll}\text { - } & 4 \text { Normal } \\
\text { - } & 6 \text { Over-weight }\end{array}$ \\
\hline 5 & Smoking habit & $\begin{array}{ll} & 3 \text { Smokers } \\
\text { - } & 7 \text { Non-smokers }\end{array}$ \\
\hline 6 & Sweetener preference & $\begin{array}{l}\text { - } 9 \text { Simple sugar } \\
\text { - } 1 \text { Jaggery }\end{array}$ \\
\hline 7 & Use of sugar & $\begin{array}{ll}\text { - } & 5 \text { Table sugar } \\
\text { - } & 4 \text { Brown sugar } \\
\text { - } & 1 \text { Jaggery }\end{array}$ \\
\hline
\end{tabular}

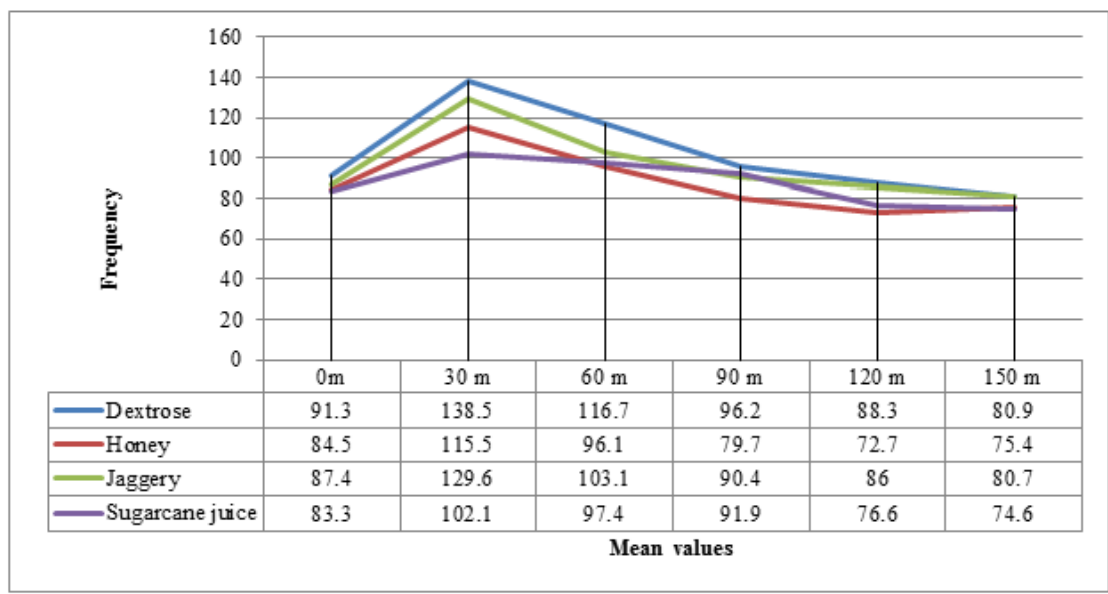

Fig-1: Mean glycemic response of Participants after consumption of honey jaggery sugarcane juice and glucose

According to the results at 0 -minute glucose response in blood was 91.3 , honey shows 84.5 , jaggery shows 87.4 and sugarcane juice shows 83.3 of means values. And after 30 minutes dextrose shows highest mean value which is 138.5 among all other products (honey, jaggery, sugarcane juice) i.e. 115.5, 129.6, 102.1 respectively. After 60 minutes again dextrose was at peak point of mean values of 116.7 among all other products (honey, jaggery, sugarcane juice) i.e. 96.1, 103.1, 97.4 respectively. After 90 minutes again dextrose was at top of mean values which is 96.2 among all other products (honey, jaggery, sugarcane juice) with the means values of 79.7, 90.4, and 91.9 respectively. After 120 minutes once again, dextrose mean value was at peak point which is 88.3 among other 3 products (honey, jaggery, and sugarcane juice) which have the mean values of $72.7,86$, and 76.6 respectively. And after 150 minutes dextrose means values was at peak point which is 80.9 among all other products (honey, jaggery, sugarcane juice) with the means values of $75.4,80.7$, and 74.6 respectively as shown in Figure 1.

\section{DISCUSSION}

In current study total of 10 subjects were included 5 males and 5 females aged between 18- 44 years. Out of 10 participants 6 subjects were slightly overweight according to BMI measures and only 3 were addicted smokers having varied sleep patterns between 8-12 hours.

In a comprehensive study by Uma $\mathrm{P}$ et al., an investigation was carried out to discover the glycemic indices of jaggery, honey and sucrose that honey can be recommended as alternative sweetener for sucrose or not. They suggested that glycemic index for jaggery; sucrose and honey were practically comparative, recommending that jaggery, sucrose and honey are all similarly hyperglycemic. Thus, honey and jaggery can't be suggested as an elective sugar for sucrose [18]. Results of present study shows that dextrose has highest glycemic index starting at 91.3 at 0 min then comes honey at 84.5 , jaggery at 87.4 and sugarcane juice at 83.3. And after 30 minutes dextrose shows highest mean value which is 138.5 among all other products i.e. $115.5,129.6,102.1$ respectively. After 60 minutes again dextrose was at peak point of mean value of 116.7 among all other products i.e. 96.1, 103.1, 97.4 respectively. After 90 minutes again dextrose was at top of mean values which is 96.2 among all other products with the means values of $79.7,90.4$, and 91.9 respectively. After 120 minutes once again, dextrose 
mean value was at peak point which is 88.3 among other 3 products which have the mean values of 72.7 , 86, 76.6 respectively. And after 150 minutes dextrose means values was at peak point which is 80.9 among all other products with the means values of $75.4,80.7$, and 74.6 respectively. Thus, recommending that honey, sugarcane juice and jaggery can be used by healthy individuals.

\section{CONCLUSIONS}

Study concluded that glycemic response of honey, jaggery and sugarcane juice showed that all had good glycemic response except dextrose which had high glycemic response. So, natural sweeteners such as honey jaggery sugarcane juice are better options for healthy individuals.

\section{REFERENCES}

1. Kannar, D., Kitchen, B.J., inventors; Horizon Science Pty Ltd, assignee. (2012). Natural sweetener. United States patent US, 112(5):109968.

2. Rana, S., Sharma, S., Katare, C., Shrivatava, V., Prasad, G.B. (2012). Glycemic response and glycemic index of common sweeteners and honey incorporated products. IOSR J Nurs Health Sci, 1 , 40-4.

3. Anderson, G.H., Cho, C.E., Akhavan, T., Mollard, R.C., Luhovyy, B.L., Finocchiaro, E.T. (2010). Relation between estimates of cornstarch digestibility by the Englyst in vitro method and glycemic response, subjective appetite, and shortterm food intake in young men. The American journal of clinical nutrition, 91(4), 932-939.

4. Augustin, L.S., Kendall, C.W., Jenkins, D.J., Willett, W.C., Astrup, A., Barclay, A.W., Björck, I., Brand-Miller, J.C., Brighenti, F., Buyken, A.E., Ceriello, A. (2015). Glycemic index, glycemic load and glycemic response: an International Scientific Consensus Summit from the International Carbohydrate Quality Consortium (ICQC). Nutrition, Metabolism and cardiovascular diseases, 25(9), 795-815.

5. Zhu, Y., Hsu, W.H., Hollis, J.H. (2013). The impact of food viscosity on eating rate, subjective appetite, glycemic response and gastric emptying rate. PLoS One, 8(6), e67482.

6. Priya, K., Gupta, V.R., Srikanth, K. (2011). Natural sweeteners: A complete review. Journal of Pharmacy Research, 4(7), 2034-2039.

7. Ludwig, D. S. (2002). The glycemic index: physiological mechanisms relating to obesity, diabetes, and cardiovascular disease. Jama, 287(18), 2414-2423.

8. Liu, S., Willett, W.C., Stampfer, M.J., Hu, B., Franz, M., Sampson, L., Hennekens, C.H., Manson, J.E. (2000). A prospective study of dietary glycemic load, carbohydrate intake, and risk of coronary heart disease in US women. The American journal of clinical nutrition, 71(6), 14551461.

9. American Diabetes Association. (2015). Standards of medical care in diabetes-2015 abridged for primary care providers. Clinical diabetes: $a$ publication of the American Diabetes Association, 33(2), 97.

10. Dixon, J.B., Chuang, L.M., Chong, K., Chen, S.C., Lambert, G.W., Straznicky, N.E., Lambert, E.A., Lee, W.J. (2013). Predicting the glycemic response to gastric bypass surgery in patients with type 2 diabetes. Diabetes care, 36(1), 20-26.

11. Anton, S.D., Martin, C.K., Han, H., Coulon, S., Cefalu, W.T., Geiselman, P., Williamson, D.A. (2010). Effects of stevia, aspartame, and sucrose on food intake, satiety, and postprandial glucose and insulin levels. Appetite, 55(1), 37-43.

12. Jakobsen, M.U., Dethlefsen, C., Joensen, A.M., Stegger, J., Tjønneland, A., Schmidt, E.B., Overvad, K. (2010). Intake of carbohydrates compared with intake of saturated fatty acids and risk of myocardial infarction: importance of the glycemic index. The American journal of clinical nutrition, 91(6), 1764-1768.

13. Shera, A.S., Jawad, F., Maqsood, A. (2007). Prevalence of diabetes in Pakistan. Diabetes research and clinical practice, 76(2), 219-222.

14. Atkinson, F.S., Foster-Powell, K., Brand-Miller, J.C. (2008). International tables of glycemic index and glycemic load values: 2008. Diabetes care, 31(12), 2281-2283.

15. Solomon, T.P., Haus, J.M., Kelly, K.R., Cook, M.D., Filion, J., Rocco, M., Kashyap, S.R., Watanabe, R.M., Barkoukis, H., Kirwan, J.P. (2010). A low-glycemic index diet combined with exercise reduces insulin resistance, postprandial hyperinsulinemia, and glucose-dependent insulinotropic polypeptide responses in obese, prediabetic humans. The American journal of clinical nutrition, 92(6), 1359-1368.

16. Drakos, S.G., Pagani, F.D., Lundberg, M.S., Baldwin, J.T. (2017). Advancing the science of myocardial recovery with mechanical circulatory support: a working group of the national, heart, lung, and blood institute. JACC: Basic to Translational Science, 2(3), 335-340.

17. Houry, D.E., Salhi, B.A. (2014). Acute complications of pregnancy. Rosen's Emergency Medicine: Concepts and Clinical Practice. 8th ed. Philadelphia, PA: Elsevier Saunders. 94(4):136092

18. Uma, P., Hariharan, R.S., Ramani, V., Seshia, V. (1987). Glycaemic indices of different sugars. International Journal of Diabetes in Developing Countries, 7, 78-82. 